\title{
Iturin Levels on Wheat Spikes Linked to Biological Control of Fusarium Head Blight by Bacillus amyloliquefaciens
}

\author{
J. M. Crane, D. M. Gibson, R. H. Vaughan, and G. C. Bergstrom
}

First, second, third, and fourth authors: Department of Plant Pathology and Plant-Microbe Biology, 334 Plant Science Bldg., Cornell University, Ithaca, NY 14853; and second and third authors: U.S. Department of Agriculture-Agricultural Research Service, Robert W. Holley Center for Agriculture and Health, Tower Road, Ithaca, NY 14853.

Accepted for publication 3 October 2012.

\begin{abstract}
Crane, J. M., Gibson, D. M., Vaughan, R. H., and Bergstrom, G. C. 2013. Iturin levels on wheat spikes linked to biological control of Fusarium head blight by Bacillus amyloliquefaciens. Phytopathology 103:146-155.

The TrigoCor strain of Bacillus amyloliquefaciens provides consistent control against Fusarium head blight of wheat in controlled settings but there is a lack of disease and deoxynivalenol suppression in field settings. Since production of antifungal compounds is thought to be the main mode of action of TrigoCor control, we quantified levels of a key family of antifungal metabolites, iturins, as well as monitored Bacillus populations on wheat spikes over 14 days post-application in both the green-

house and the field. We found that initial iturin levels on spikes in the greenhouse were three times greater than on spikes in the field, but that by 3 days post-application, iturin levels were equivalent and very low in both settings. We also determined that iturins declined rapidly over a 3-day post-application period on wheat spikes in both environments, despite the presence of significant Bacillus populations. Greenhouse trials and antibiosis tests indicated that the lower iturin levels on wheat spikes in the field could be a major factor limiting disease control in field settings. Future efforts to improve Bacillus disease control on wheat spikes and in the phyllosphere of various plants should focus on maintaining higher levels of iturins over critical infection periods.
\end{abstract}

Managing fungal diseases of plants with the gram-positive bacterium Bacillus subtilis or the closely related B. amyloliquefaciens, either as an alternative or a supplement to fungicides, could be of great benefit. Biological control agents (BCAs) such as Bacillus spp. are attractive for disease control due to their low environmental impact, and due to their ability to help reduce growers' dependence on chemicals, thereby slowing the development of fungicide resistance in pathogen populations (24). There have been notable successes with Bacillus BCAs applied in the soil (40), whereas biological control of fungal diseases by BCAs applied to aerial plant parts has been more challenging (23). Several Bacillus BCAs have shown consistent suppression of aerial diseases under controlled environments, but have shown less consistent control under field conditions. However, few studies pinpoint the reasons for failed disease control by Bacillus BCAs in the field.

The TrigoCor strain of $B$. amyloliquefaciens is one such Bacillus BCA, that when applied to above-ground plant surfaces, is unable to consistently control disease in the field, despite reproducibly suppressing disease in the greenhouse $(6,12,26,52)$. Like many Bacillus biocontrol strains, TrigoCor shows potential as a BCA because it produces a diverse arsenal of antifungal metabolites in culture. Production of these compounds, particularly cyclic lipopeptides in the iturin and fengycin families, is believed to be the main mechanism through which TrigoCor (14, 42) and other Bacillus BCAs (36) inhibit fungal spore germination and growth on plant surfaces, prior to pathogen invasion of

Corresponding author: G. C. Bergstrom; E-mail address: gcb3@ cornell.edu

* The $\boldsymbol{e}$-Xtra logo stands for "electronic extra" and indicates that the online version contains two supplemental figures and one supplemental table.

http://dx.doi.org/10.1094/PHYTO-07-12-0154-R

This article is in the public domain and not copyrightable. It may be freely reprinted with customary crediting of the source. The American Phytopathological Society, 2013 plant tissues. In addition to the production of antifungal compounds, another aspect of TrigoCor and other Bacillus species which make them promising as BCAs is that they can transition to a spore form in adverse environmental conditions, thereby potentially extending their lifespans on aerial plant surfaces.

TrigoCor has been evaluated extensively for control of Fusarium head blight (FHB) of wheat $(11,12,20,26,47,53)$, caused in the United States by the filamentous ascomycete Fusarium graminearum Schwabe (teleomorph: Gibberella zeae (Schwein.) Petch). Management of this disease is currently challenged by the general lack of highly resistant wheat cultivars (4), and by variable or incomplete control by currently available fungicides $(8,32,33$, 39,54). A major obstacle to FHB management using chemical control is that $F$. graminearum infections can occur beyond the 30-day preharvest interval when fungicides can be legally applied $(18,31)$. These late-season infections contribute to accumulation of the Fusarium-produced mycotoxin deoxynivalenol (DON) $(10,15)$, and consequently, to rejection or severe dockage of grain at grain elevators or flour mills. Because there are no restrictions on application timings of BCAs, a BCA sprayed onto wheat spikes either with or following a fungicide could add significantly to an integrated management plan by protecting against lateseason infections, particularly if the BCA could survive and be active for long periods of time on wheat surfaces. In addition to this potential role of BCAs in managing FHB within conventional wheat production, BCAs could also be a valuable tool for managing FHB in organic systems, for which control measures are severely limited. In addition to TrigoCor, several other BCAs have been evaluated for control of FHB, including yeasts and both gram-positive and gram-negative bacteria $(7,14,25,27-29,38,55)$; however, many exhibit the same problems with consistency when it comes to field applications $(25,46)$.

Using TrigoCor as a model BCA, we sought to identify the key factors that influence the success or failure of Bacillus-based disease control on aerial plant surfaces. Understanding why TrigoCor frequently fails at controlling FHB in the field despite being 
consistently effective in the greenhouse should allow the formulation of intelligent strategies for enhancing biocontrol effectiveness in the field.

We hypothesize that the success of disease control depends on the presence of sufficient levels of viable Bacillus populations and/or of Bacillus-produced antifungal metabolites over critical infection periods. Our objectives in this study were to assess viable cell populations and antifungal metabolite levels over time on wheat spikes in the greenhouse and in the field, and to relate these data to FHB/DON suppression.

\section{MATERIALS AND METHODS}

Microbial cultures. B. amyloliquefaciens strain TrigoCor was isolated from the wheat rhizosphere and selected for further study based on its consistent ability to inhibit the growth of common cereal crop pathogens, including $F$. graminearum, in antibiosis assays (6). TrigoCor, previously described as B. subtilis, was properly identified as $B$. amyloliqeufaciens based on phylogenetic analysis following the method of Rooney et al. (44).

For inoculum production, TrigoCor liquid starter cultures were grown for $48 \mathrm{~h}$ in nutrient broth plus yeast extract (NBYE; $8 \mathrm{~g}$ of Difco nutrient broth (Becton, Dickinson and Company, Franklin Lakes, NJ), $7 \mathrm{~g}$ of Bacto yeast extract (Becton, Dickinson and Company), 1 liter of RO water), then were transferred 1:1,000 to $100 \mathrm{ml}$ aliquots of NBYE medium amended with $0.1 \mathrm{mM}$ $\mathrm{MnSO}_{4} \cdot \mathrm{H}_{2} \mathrm{O}$ (NBYE.Mn) and grown for 5 days. For the 2009 field trials, inoculum was grown in 1-liter aliquots for 7 days. Unless otherwise noted, cultures were grown at room temperature (22 to $26^{\circ} \mathrm{C}$ ) with shaking $(155 \mathrm{rpm})$ to stationary phase. In the 2011 field season, inoculum was grown in 1-liter aliquots; however, due to an earlier than expected wheat flowering and consequently, a rapid need for inoculum, the cultures were grown for 2 days at elevated temperature, $30^{\circ} \mathrm{C}$, to reach stationary phase. For each experiment, culture aliquots were combined just prior to inoculations; samples of inoculum were set aside at 4 and $-80^{\circ} \mathrm{C}$ for later quantification of viable cell populations and metabolites, respectively.

F. graminearum strain Gz014 NY98 was isolated from an FHBinfected wheat spike. Cultures were grown on Difco potato dextrose agar (PDA) (Becton, Dickinson and Company) at room temperature with $12 \mathrm{~h} \mathrm{UV} \mathrm{(40} \mathrm{W,} 350 \mathrm{~nm}$ ) light/day for approximately 14 days, and then conidia were transferred to fresh PDA and were grown under the same conditions for an additional 13 to 15 days. Conidia were filtered through a 250 micron sieve (Dual Manufacturing Company, Chicago) to remove mycelia prior to use.

Standard greenhouse bioassay. Seeds of 'Norm' spring wheat were sown in soilless Cornell Mix ( 3 to $3.8 \mathrm{ft}^{3}$ of compressed peat moss, 2 to $6 \mathrm{ft}^{3}$ of vermiculite, $20 \mathrm{lbs}$. of dolomitic limestone, 6 lbs. of 11-5-11 fertilizer) in 6-in clay pots at 10 seeds/pot. Plants were grown for roughly 8 weeks in the greenhouse at 25 to $35^{\circ} \mathrm{C}$ under 12 to $14 \mathrm{~h}$ light/day and then were trimmed to 10 spikes per pot. For TrigoCor inoculations, approximately $30 \mathrm{ml}$ of TrigoCor inoculum was sprayed onto spikes in a single pot using a pressurized Preval Spray Gun (Preval, Coal City, IL). Unless otherwise noted, control spikes were treated with deionized water. The day after TrigoCor application, spikes in each pot were sprayed with roughly $30 \mathrm{ml}$ of $F$. graminearum conidia $\left(6 \times 10^{4}\right.$ spores/ $\mathrm{ml}$ ) using a household handheld sprayer (Consolidated Plastics, Stow, $\mathrm{OH}$ ). During TrigoCor and $F$. graminearum inoculations, pots were rotated 45 degrees so that each was sprayed in eight positions. Following $F$. graminearum application, pots were placed into a mist chamber for $48 \mathrm{~h}$ and then into a controlled climate chamber set at $25.5^{\circ} \mathrm{C}, 14 \mathrm{~h}$ light $/ 9 \mathrm{~h}$ dark cycle where they remained until harvest. Appearance of disease symptoms, characterized by spikelet bleaching and bending of awns, was monitored daily until symptoms stabilized at approximately 12 days post- $F$. graminearum application, when FHB severity (percentage of symptomatic spikelets per spike) and incidence (percentage of symptomatic spikes per pot) were recorded.

Population dynamics of Bacillus on wheat spikes in the greenhouse. Three greenhouse experiments to investigate Bacillus temporal population dynamics on wheat spikes were conducted using the standard greenhouse protocol. In the representative experiment presented, inoculum Bacillus cell concentration was $1.1 \times 10^{9} \mathrm{CFU} / \mathrm{ml}$, and spikes were sprayed at anthesis (Feekes growth stage 10.51). Control pots were nontreated. Plants were not challenged with $F$. graminearum and were therefore not rated for FHB index. There were seven replicates per treatment and two pots per replicate. For population quantification at each time point, two spikes from each pot in a given replicate were collected and combined for processing (four spikes total per replicate).

Population dynamics of Bacillus on wheat spikes in the field. Field trials were conducted all years at the Ithaca field site (IFS) in Cornell's Fusarium head blight nursery in Ithaca, NY, and in 2009 and 2010 at the Aurora field site (AFS) in Cornell's Musgrave Research Farm in Aurora, NY. At IFS, wheat was irrigated for $12 \mathrm{~h} /$ day at a rate of $30 \mathrm{~s}$ on and $4.5 \mathrm{~min}$ off. Wheat at AFS was not irrigated. At IFS, rows were planted with 'Caledonia' winter wheat in all years and were roughly $1 \mathrm{~m}$ long with approximately 150 spikes/row. At AFS, rows of 'Jensen' (2009) and 'Pioneer 25R47' (2010) winter wheat were marked off within larger fields, and each row was on average $1.3 \mathrm{~m}$ long with 100 wheat spikes/row.

In the 2009 trials, spikes were either nontreated or treated with TrigoCor ("TrigoCor low"). In 2010, two application rates (Table 1, Supplemental Table 1) of the same TrigoCor inoculum were applied to wheat spikes as a "high" volume and a "low" volume TrigoCor treatment, and control spikes were nontreated.

Spikes were sprayed with TrigoCor at anthesis (Feekes growth stage 10.52 in 2009 and 10.51 in 2010). The following day, Fusarium conidia $\left(1 \times 10^{5}\right.$ conidia/ml $)$ were sprayed onto wheat spikes using an R\&D Sprayer $\left(\mathrm{CO}_{2}\right)$, Model GS set at a pressure of approximately 30 psi, with 4 fan nozzles at 19 " $(48 \mathrm{~cm})$. In 2010 at AFS, Fusarium was sprayed onto spikes 3 to 4 h postTrigoCor application.

Each treatment consisted of 13 replicates in 2009 and 10 replicates in 2010. In 2009 there were two rows per replicate; however, representative data showing population data, FHB index, and DON are only reported from the first row within each replicate. In 2010, each replicate was one row. Treatments in 2009 were alternating and in 2010 were arranged in a randomized block design, with replicate as the blocking factor. In 2009 there was one nontreated row separating treatments, and in 2010 there were five nontreated rows separating treatments.

Disease data were estimated once incidence levels had stabilized. In 2009 at IFS, incidence data were collected from 50 spikes tagged with colored time tape (VWR, Batavia, IL) prior to TrigoCor spray, and severity data were collected from 10 representative symptomatic spikes. At AFS in 2009 and at both field sites in 2010, incidence ratings were taken from entire rows and severity was recorded based on 10 representative symptomatic spikes per row. Severity was quantified using an FHB severity scale (17).

Bacillus population quantification. At $0,1,3,7$, and 14 days post-TrigoCor application, wheat spikes were collected from either the greenhouse or the field and stored in a $-80^{\circ} \mathrm{C}$ freezer until processing. The 0 day samples were collected after wheat spikes had dried following Bacillus spray, usually 4 to 5 h post-spray. In the greenhouse, the 1 day sample was collected prior to pots being transferred to the mist chamber, and the 3 day sample was collected after pots were removed from the mist chamber and spikes had fully dried. In the 2009 field trials, spikes were marked for collection prior to TrigoCor inoculations. In the 2010 field trials, representative spikes were collected randomly from various positions within each row. 
Bacterial quantification was conducted as described in Jochum et al. (25), with the modification that the phosphate buffer was amended with $0.1 \%$ Triton X-100. Colonies were counted based on similarity to typical TrigoCor morphology.

Background Bacillus level on spikes in the greenhouse and field. Wheat spikes were collected prior to application of any treatments to assess the starting background level of Bacillus on wheat surfaces. From the greenhouse, a total of four samples from two separate experiments were collected and processed using the standard protocol. For the 2010 field sites, two samples were collected at IFS and one sample was collected at AFS.

Estimation of Bacillus population present as spores. The percentage of Bacillus cells present in the spore form was evaluated for three replicates per treatment per time point from a greenhouse experiment and from both field locations in 2010. Samples were removed from the dilution series made to measure population dynamics, and then were heated at $85^{\circ} \mathrm{C}$ for $10 \mathrm{~min}$ to kill vegetative cells, and plated. Colony numbers were compared with the corresponding counts from the non-heat-treated dilution series to calculate percent spores.

Estimation of inoculum delivery to wheat spikes. To estimate the amount of Pyranine dye delivered to wheat spikes at different application rates and in different environments, a solution of Pyranine 10G dye (Keystone, Aniline Inc., Chicago, IL) (0.5 g/liter of water) was sprayed onto spikes in the greenhouse using the typical protocol; onto $1 \mathrm{~m}$ rows of Caledonia in IFS by hand at $65 \mathrm{ml} /$ row or $250 \mathrm{ml} /$ row; and onto a plot of Pioneer 25R47 in AFS with a backpack sprayer at 187 liters/ha. All field applications were conducted in 2012. The application rates used on Caledonia are equivalent to the rates used for the low and high TrigoCor applications in the 2010 field season. For each environment and application rate, 50 treated spikes were collected. Ten nontreated spikes per cultivar were also collected and processed as negative controls. Stalks were removed, and then spikes were dipped 20 times in $20 \mathrm{ml}$ of water in glass tubes $(13 \mathrm{~mm} \times$ $100 \mathrm{~mm}$ ) to remove dye, and the absorbance of the resulting solution was measured at $400 \mathrm{~nm}$ on a Spectronic 20 spectrophotometer. The amount of dye delivered to spikes was calculated using the linear fit equation from the standard curve (Supplemental Figure 1).

Time course of metabolite dynamics. For studies on metabolite dynamics in the field at AFS in 2010, blocks within a field of 'AC Superb' spring wheat were used. A high and a low application volume of TrigoCor inoculum were applied (Table 1), and the control block was nontreated. Plots were not inoculated with $F$. graminearum. There was one block per treatment and one to three block lengths between treatments. At 0,1 , and 3 days postTrigoCor application, three sets of 100 spikes were collected from each treatment block for quantification of metabolites, and two sets of four spikes were collected for quantification of populations. The 0 day sample was taken 2 to $3 \mathrm{~h}$ after TrigoCor application, after wheat spikes had dried. Incidence and severity were recorded from 10 spike samples selected from the corners and center of each plot.

Three experiments were conducted to determine the fate of iturin metabolites on wheat spikes in the greenhouse. In each experiment, pots of wheat at anthesis (Feekes growth stage 10.53) were sprayed with TrigoCor and $F$. graminearum using the standard greenhouse protocol. Inoculum cell and metabolite concentrations for the three experiments were $7.2 \times 10^{8} \mathrm{CFU} / \mathrm{ml}$ and $0.64 \mathrm{mg} / \mathrm{ml} ; 6.2 \times 10^{8} \mathrm{CFU} / \mathrm{ml}$ and $0.39 \mathrm{mg} / \mathrm{ml}$; and $8.8 \times$ $10^{8} \mathrm{CFU} / \mathrm{ml}$ and $0.22 \mathrm{mg} / \mathrm{ml}$.

During the course of each greenhouse trial, sets of 100 TrigoCortreated wheat spikes were collected from 10 pots at 0 (all trials), 1 (trials 1 and 3 ), and 3 (trials 2 and 3 ) days post-TrigoCor application. Control spikes were treated with deionized water and collected at the 0 day time point. The 0 day sample was taken 4 to $5 \mathrm{~h}$ after TrigoCor application, after wheat spikes had dried. In the third trial, Bacillus population dynamics were estimated from one four-spike replicate per treatment at each time point. Data from experiments were combined for analysis.

Bacillus metabolite quantification. Wheat spikes for metabolite analysis were placed into individual freezer bags and stored at $-80^{\circ} \mathrm{C}$ prior to extraction. Bulk samples consisting of 100 wheat spikes were placed upside down into a beaker containing approximately $500 \mathrm{ml}$ of methanol to cover the spike surfaces and then

TABLE 1. Inoculum concentrations and application rates, and ineffective disease control in field experiments using the biocontrol agent Bacillus amyloliquefaciens strain TrigoCor

\begin{tabular}{|c|c|c|c|c|c|c|c|}
\hline \multirow[b]{2}{*}{ Year } & \multirow[b]{2}{*}{ Location } & \multirow[b]{2}{*}{ Treatment } & \multicolumn{3}{|c|}{ TrigoCor inoculum characteristics } & \multicolumn{2}{|c|}{ FHB disease parameters } \\
\hline & & & Cells $(\mathrm{CFUs} / \mathrm{ml})^{\mathrm{u}}$ & Iturins $(\mathrm{mg} / \mathrm{ml})^{\mathrm{v}}$ & Volume applied (ml/spike) ${ }^{\mathrm{w}}$ & FHB index ${ }^{x}$ & $\mathrm{DON}(\mathrm{ppm})^{\mathrm{y}}$ \\
\hline \multirow[t]{2}{*}{2009} & Aurora & TrigoCor low & $4.4 \times 10^{8}$ & 0.12 & 0.4 & $16 \pm 2$ & $19.90 \pm 5.77$ \\
\hline & & Nontreated & - & - & - & $15 \pm 2$ & $12.43 \pm 3.86$ \\
\hline \multirow[t]{2}{*}{2009} & Ithaca & TrigoCor low & $3.8 \times 10^{8}$ & 0.13 & 0.8 & $21 \pm 3$ & $20.10 \pm 1.74$ \\
\hline & & Nontreated & - & - & - & $24 \pm 3$ & $17.20 \pm 1.75$ \\
\hline \multirow[t]{3}{*}{2010} & Aurora & TrigoCor low & $8.6 \times 10^{8}$ & 0.08 & 0.3 & $9 \pm 2$ & $3.28 \pm 0.25 \mathrm{a}$ \\
\hline & & TrigoCor high & $8.6 \times 10^{8}$ & 0.08 & 1.0 & $4 \pm 1$ & $1.96 \pm 0.29 b$ \\
\hline & & Nontreated & - & - & - & $10 \pm 4$ & $3.25 \pm 0.67 \mathrm{ab}$ \\
\hline \multirow[t]{3}{*}{2010} & Ithaca & TrigoCor low & $7.7 \times 10^{8}$ & 0.03 & 0.5 & $8 \pm 1$ & $4.41 \pm 0.15 \mathrm{y}$ \\
\hline & & TrigoCor high & $7.7 \times 10^{8}$ & 0.03 & 2.1 & $6 \pm 1$ & $4.04 \pm 0.28 \mathrm{y}$ \\
\hline & & Nontreated & - & - & - & $7 \pm 1$ & $2.78 \pm 0.20 x$ \\
\hline \multirow[t]{3}{*}{2010} & Aurora ${ }^{z}$ & TrigoCor low & $7.0 \times 10^{8}$ & 0.05 & 0.5 & $20 \pm 5$ & 0.81 \\
\hline & & TrigoCor high & $7.0 \times 10^{8}$ & 0.05 & 1.1 & $14 \pm 3$ & 0.72 \\
\hline & & Nontreated & - & - & - & $18 \pm 7$ & 1.20 \\
\hline
\end{tabular}

"Inoculum Bacillus cell concentrations, quantified by dilution plating. Corresponding population levels on wheat spikes are shown in Figures 2 and 3.

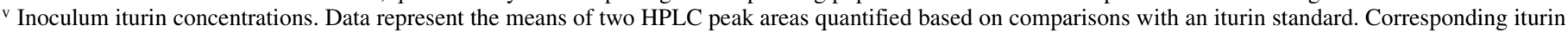
levels on wheat spikes for the 2010 spring wheat experiment are shown in Figure 3.

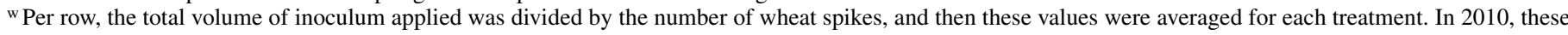
amounts correspond to the 'high' and 'low' designations in the treatment names.

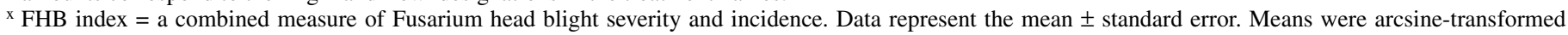
prior to separation by $t$ test in 2009 and analysis of variance (ANOVA) followed by Tukey's honestly significant difference (HSD) in 2010. There were no statistically significant differences between treatments in $2009(P=0.6409$ for Ithaca and $P=0.8300$ for Aurora $), 2010$ population dynamics trials $(P=0.3938$ for Ithaca and $P=0.1695$ for Aurora), or 2010 metabolite dynamics trial $(P=0.7729)$.

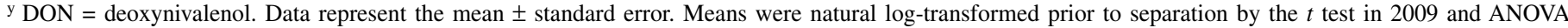
followed by Tukey HSD in 2010 . Means followed by the same letter were statistically different in 2010 population dynamics trials $(P<0.0001$ for Ithaca and $P=$ 0.0118 for Aurora). There were no statistically significant differences between treatments in $2009(P=0.2282$ for Ithaca and $P=0.2927$ for Aurora).

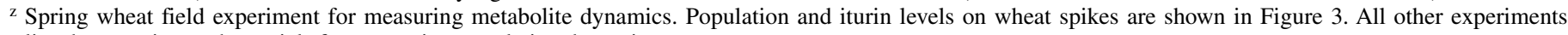
listed were winter wheat trials for measuring population dynamics. 
sonicated for $10 \mathrm{~min}$. The mixture was filtered using a Buchner funnel, and the filtrate was evaporated to dryness on a rotoevaporator under minimal heat. The residue was then reconstituted into $1 \mathrm{ml}$ of methanol, of which $100 \mu \mathrm{l}$ was filtered through a $0.4 \mu \mathrm{m}$ PTFE syringe filter for high-performance liquid chromatography (HPLC) analysis using a modification of the method as described (41). HPLC employed a Polaris RP C18-A column (Varian, $5 \mu \mathrm{m}, 250 \mathrm{~mm} \times 4.6 \mathrm{~mm}$ ) column, using a gradient of solvent A-acetonitrile containing $0.1 \%$ trifluoroacetic acid and solvent B-HPLC-grade water with $0.1 \%$ trifluoroacetic acid, flow rate of $1 \mathrm{ml} / \mathrm{min}$. Gradient conditions were as follows: $30 \% \mathrm{~A}$ : $70 \%$ B for 2 min, linear gradient to $65 \%$ A:35\% B over 35 min; linear gradient to $90 \% \mathrm{~A}: 10 \% \mathrm{~B}$ over $10 \mathrm{~min}$, and then held for 10 min prior to return to starting conditions at $55 \mathrm{~min}$ and held for 10 min prior to the next injection. Primary detection was by UV at $220 \mathrm{~nm}$ (extracted from a 190 to $350 \mathrm{~nm}$ scan on a Waters 996 diode array detector). Iturins were estimated using an external standard containing primarily iturin $\mathrm{A}$ as well as two minor iturins with longer fatty acid tails (Sigma Chemical Co., St. Louis, MO) using a five point calibration curve and integrated areas for the peaks in extract chromatograms that matched the retention times and spectral scans of the authentic standard (Sigma Chemical).

For quantification of iturins on wheat spikes, two peaks in the HPLC chromatogram that showed good separation from the background trace of control plants and that had the same retention time and spectral identity as those in an iturin A standard were chosen (Supplemental Figure 2). Their identity as iturins had also been confirmed in earlier studies of TrigoCor by MS analysis (41). These two peaks were also easily visible in HPLC traces from extracted broth samples and therefore were useful as specific biomarkers to follow the time course of metabolites on the wheat spike surface. To further confirm identities of these peaks, electrospray mass spectra of standard mixtures of iturin (Sigma Chemical), fermentation extracts, and wheat spike extracts were analyzed by direct infusion of methanolic solutions into the mass detector at a flow rate of $1 \mu \mathrm{l} / \mathrm{min}$ using a syringe pump (Model 55-1199; Harvard Apparatus, Holliston, MA). Detection in the positive ion mode gave major quasimolecular ions $[\mathrm{M}+\mathrm{Na}]$ of iturins at 1065 and 1079 using a cone voltage of $80 \mathrm{~V}$, and a capillary voltage of $4.0 \mathrm{kV}$, source block temperature held at $100^{\circ} \mathrm{C}$, and desolvation gas $\left(\mathrm{N}_{2}\right)$ heated to $150^{\circ} \mathrm{C}$.

Concentration effects of TrigoCor inoculum. Three greenhouse experiments were conducted according to the standard protocol using full-strength TrigoCor inoculum as well as inoculum diluted 10- and 100-fold dilutions in deionized water.
There were seven replicates per treatment for measuring FHB symptoms and one replicate per treatment for examining Bacillus population levels at 0 days and 14 days post-application where each replicate was one pot. Spikes were sprayed with TrigoCor and $F$. graminearum at anthesis (Feekes growth stage 10.53). Wheat spikes were collected following application on day 0 , and after 14 days, and processed for Bacillus populations. Iturin levels on wheat spikes were calculated based on the iturin concentration in the inoculum (Table 2) and on the average volume delivered to wheat spikes in greenhouse experiments.

Agar well diffusion assay. Five hundred microliters of $F$. graminearum conidial suspension $\left(1 \times 10^{5}\right.$ conidia/ml $)$ was uniformly spread on the surface of plates $(100 \times 15 \mathrm{~mm})$ containing $15 \mathrm{ml}$ of PDA. After plates had dried (approximately $60 \mathrm{~min}$ ), a 4.72-mmdiameter cork borer was used to cut holes in the agar. Holes were filled with $29 \mu \mathrm{l}$ of a freshly made serial dilution of an iturin A standard (Sigma Chemical) in $9 \%$ methanol and with a 5-day TrigoCor culture filtered through a $0.1 \mu \mathrm{m}$ filter. Prosaro (prothioconazole 1.76 + tebuconazole $1.76 \mathrm{lb}$. ai/gal. $)(0.3 \%$, vol $/ \mathrm{vol})$ and $9 \%$ methanol were used as positive and negative controls, respectively. The Prosaro was diluted to a concentration similar to that recommended for use in the field $(6.5 \mathrm{fl}$. oz./20 gal.). There were three replicates/sample and each replicate was on a separate plate, although a single plate contained up to five different samples. Plates were incubated at room temperature under $12 \mathrm{~h} \mathrm{UV}$ light/day for 6 days. At 6 days, inhibition zone measurements were taken using a digital caliper along two perpendicular lines drawn to intersect in the center of the sample well. Inhibition zone lengths were measured from the edge of the well to the edge of the zone of inhibition. Minimum inhibitory concentration was defined as the smallest iturin concentration that produced a zone of inhibition. The assay was repeated three times.

Effect of repeated Bacillus applications in the field. To examine the effect on disease control of repeated TrigoCor applications, wheat was grown and irrigated as above for a field trial (IFS). There were four treatments: nontreated, TrigoCor applied once (day 0), TrigoCor applied three times (day 0, 2, 4), and TrigoCor applied once (day 0) with noninoculated NBYE. Mn broth applied twice (day 2,4) to control for the effect of nutrient addition to wheat surfaces in the triple TrigoCor treatment. There were two replicates per treatment, where each replicate consisted of seven 1-m long rows, and there were four rows between treatments. Treatments were arranged in a randomized block design, with replicate as the blocking factor. At the day 0 spray time, wheat was at anthesis (Feekes 10.52). F. graminearum conidia

TABLE 2. Comparison of disease control efficacy in the greenhouse with 10- and 100-fold diluted TrigoCor inoculums

\begin{tabular}{|c|c|c|c|c|c|c|c|}
\hline \multicolumn{3}{|c|}{ TrigoCor inoculum characteristics } & \multicolumn{2}{|c|}{$\begin{array}{c}\text { Bacillus population levels on } \\
\text { wheat spikes (CFUs/spike) }{ }^{t}\end{array}$} & \multirow{2}{*}{$\begin{array}{c}\begin{array}{c}\text { Iturins on wheat } \\
\text { spikes, calculated } \\
(\mathrm{mg} / \mathrm{spike})^{\mathrm{u}}\end{array} \\
\text { Day } 0\end{array}$} & \multicolumn{2}{|c|}{ FHB disease parameters } \\
\hline Cells $(\mathrm{CFUs} / \mathrm{ml})^{\mathrm{v}}$ & Iturins $(\mathrm{mg} / \mathrm{ml})^{\mathrm{w}}$ & Volume applied (ml/spike) & Day 0 & Day 14 & & FHB index ${ }^{x}$ & $\mathrm{DON}(\mathrm{ppm})^{\mathrm{y}}$ \\
\hline $5.8 \times 10^{8}$ & 0.25 & 3.0 & $1.8 \times 10^{8}$ & $1.1 \times 10^{8}$ & 0.13 & $6 \pm 3 a$ & $6.17 \pm 2.16 \mathrm{a}$ \\
\hline $9.6 \times 10^{7}$ & 0.06 & 3.2 & $3.6 \times 10^{7}$ & $1.4 \times 10^{7}$ & 0.03 & $27 \pm 4 b$ & $28.87 \pm 5.10 b$ \\
\hline $9.3 \times 10^{6}$ & N.m. ${ }^{z}$ & 3.0 & $1.2 \times 10^{6}$ & $1.1 \times 10^{6}$ & - & $30 \pm 4 b$ & $25.93 \pm 2.14 b$ \\
\hline- & - & - & $5.2 \times 10^{4}$ & $1.1 \times 10^{4}$ & - & $33 \pm 4 b$ & $31.96 \pm 3.50 \mathrm{~b}$ \\
\hline
\end{tabular}

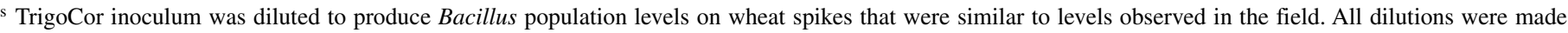
with sterile water, and water alone was applied as a negative control. Experiment was conducted three times with reproducible results. Data shown are from a representative experiment.

${ }^{\mathrm{t}}$ Inoculum Bacillus cell concentrations, quantified by dilution plating.

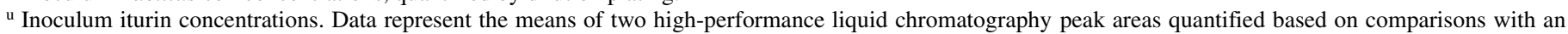
iturin standard.

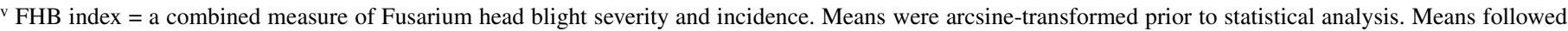
by the same letter were not statistically different $(P<0.0001)$ according to the Tukey honestly significant difference (HSD) test within the general linear model procedure. Numbers represent the mean \pm the standard error using nontransformed data.

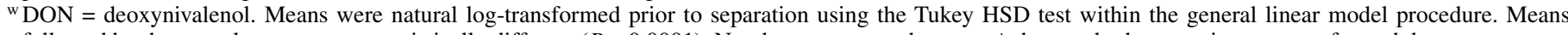
followed by the same letter were not statistically different $(P<0.0001)$. Numbers represent the mean \pm the standard error using nontransformed data.

${ }^{x}$ Quantified using dilution plating from a bulked sample of four spikes per treatment.

y Calculated based on inoculum concentration and an inoculum delivery rate of $0.5 \mathrm{ml} / \mathrm{spike}$.

z N.m. = not measurable. 
were applied the day following the first TrigoCor application as described for field trials above.

To calculate FHB incidence, all symptomatic spikes were counted per replicate per treatment, and this number was divided by total number of spikes. Spikes at the very front and back of rows were excluded. FHB severity ratings were taken from 20 representative spikes from each treatment replicate.

DON analysis. Wheat spikes in greenhouse and field experiments were harvested by hand. Grain was cleaned using a belt thresher for field experiments and by hand for greenhouse experiments and was ground with a coffee grinder (Cuisinart, Stamford, CT). DON quantification was conducted by the U.S. Wheat and Barley Scab Initiative-supported DON Testing Labs at Virginia Tech and the University of Minnesota.

Statistical analysis. FHB index was calculated by multiplying FHB incidence by FHB severity. Bacillus population levels, FHB index, and DON (ppm) were $\log _{10}$, arcsine, and natural log-transformed, respectively, prior to statistical analysis. Data were analyzed using the general linear model within the JMP statistical program version 9.0.2 (SAS Institute Inc., Cary, NC). The response variable was population level, FHB index, DON, or inhibition zone radius, and the independent variables were treatment and replicate. Means were separated by $t$ test or by Tukey's honestly significant difference (HSD) $(P=0.05)$, depending on the number of treatments. Where applicable, trends in means separation are shown for transformed means. Reported means and standard error were calculated using nontransformed data.

\section{RESULTS}

Population dynamics of Bacillus on wheat spikes in the greenhouse. The level of Bacillus populations recovered from wheat spikes was stable throughout the 14-day sampling period at $10^{8}$ Bacillus CFU/spike (Fig. 1), while the quantity of Bacillus on nontreated spikes ranged over time from $10^{4}$ to $10^{6}$ Bacillus CFU/spike. At each time point, the Bacillus populations on TrigoCortreated wheat spikes were significantly higher than on nontreated spikes $(P=0.05)$. FHB index data were not recorded; however, TrigoCor applications at the rate used in these trials have consistently resulted in significant FHB/DON control (48).

Population dynamics of Bacillus on wheat spikes in the field. In field trials at two locations over 2 years, Bacillus populations on TrigoCor-treated wheat spikes declined by 1 order of magnitude over a 14-day sampling period post-application (Fig.

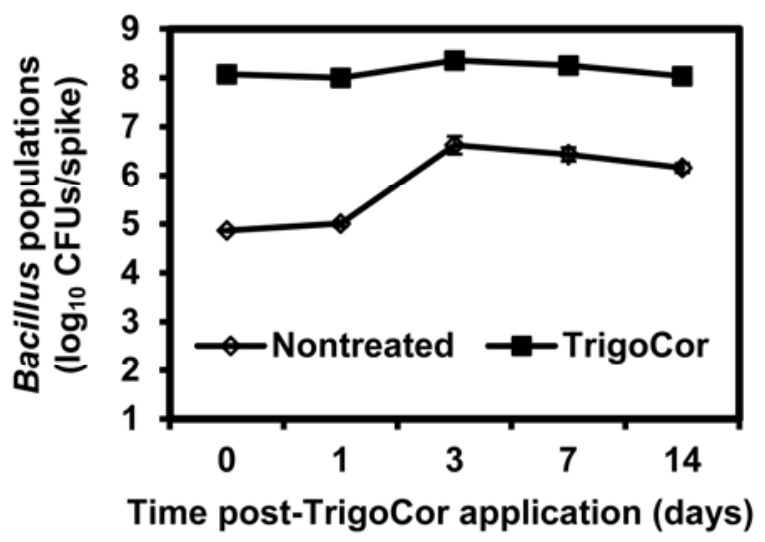

Fig. 1. Bacillus population dynamics on wheat spikes in the greenhouse following application of the biocontrol agent Bacillus amyloliquefaciens strain TrigoCor. Bacillus population levels were quantified using dilution plating. The wheat spikes were in a mist chamber from 1 to 3 days post-TrigoCor application. Experiment was repeated three times with comparable results. Data shown are from a representative experiment. Each data point represents the mean of seven replicates, using population levels from four spikes per replicate. Vertical lines represent the standard error of the mean for each treatment at each time point.
2). This trend was consistent despite differing patterns in temperature and rainfall among field locations and years. Although Bacillus populations decreased throughout the 14-day period, Bacillus was still recovered from treated wheat spikes in each experiment at significant levels at harvest.

In the 2009 field trials (Fig. 2A and B), the Bacillus population level on TrigoCor-treated wheat spikes was 1 to 2 orders of magnitude lower than the level observed at corresponding times in the greenhouse (Fig. 1) at each time point, although it was still significantly higher than on nontreated wheat spikes at all time points $(P=0.05)$. Treatment with TrigoCor did not produce any significant reductions in FHB/DON in 2009 at either field site (Table 1).

In the 2010 field trials, the high TrigoCor treatment resulted in Bacillus population levels that on days 0 and 1 were equivalent (IFS, Fig. 2C) or slightly lower (AFS, Fig. 2D) than the $10^{8} \mathrm{CFU} /$ spike observed in the greenhouse. At both field sites, the population level on spikes in the low TrigoCor treatment generally approximated the level observed on TrigoCor-treated spikes in 2009. Although the Bacillus population level on spikes remained numerically greater in the high TrigoCor treatment compared with the low TrigoCor treatment at all time points in both locations, this difference was only statistically significant $(P=$ $0.05)$ at IFS from 0 to 3 days and at AFS on all days except day 7. At all time points at both field sites the Bacillus population levels on spikes treated with the two TrigoCor treatments were significantly greater than the level on nontreated wheat spikes $(P=$ $0.05)$.

There was a numerically small but statistically significant difference in DON levels at IFS and AFS in 2010; however, in neither location did TrigoCor treatment significantly reduce DON from the nontreated control. At AFS the high TrigoCor treatment resulted in significantly less DON accumulation than the low TrigoCor treatment. There were no statistically significant differences in FHB index among treatments in either location; however, at AFS the high TrigoCor treatment resulted in a numerically lower FHB index than did the other two treatments.

Background Bacillus level on spikes in the greenhouse and field. In the greenhouse and in both field locations in 2010, the Bacillus level on wheat spikes collected prior to TrigoCor application was estimated at $10^{2} \mathrm{CFU} / \mathrm{spike}$. The two or more orders of magnitude discrepancy between this pre-TrigoCor application Bacillus level and the post-TrigoCor application level observed on nontreated spikes in the greenhouse (Fig. 1) and field (Fig. 2) suggests that a significant portion of the Bacillus recovered from nontreated spikes in our experiments resulted from the TrigoCor spray, perhaps through drift of inoculum in the air or through physical spreading of cells by insects or humans.

Estimation of Bacillus population present as spores. The percentage of spores from TrigoCor-treated spikes fluctuated in both the greenhouse and the field, but was typically 60 to $90 \%$. The percentage of spores from nontreated spikes was 60 to $90 \%$ in the field and 40 to $100 \%$ in the greenhouse. Typical TrigoCor inoculum contains 50 to $80 \%$ spores.

Estimation of inoculum delivery to wheat spikes. Pyranine dye applied at the normal greenhouse rate resulted in a volume delivered to wheat spikes that was approximately two times higher than the volume delivered to wheat spikes for the "high TrigoCor" IFS rate, one order of magnitude higher than the volume delivered to wheat spikes at the "low TrigoCor" IFS rate, and 2 orders of magnitude higher than dye delivered to wheat spikes at the rate typical for commercial spray equipment.

Time course of metabolite dynamics. In both the greenhouse and in the field samples, iturin biomarker levels on wheat spikes decreased over a 3-day period post-TrigoCor application (Fig. 3). Initially, the level of iturin biomarkers was approximately three times greater on greenhouse spikes than on field spikes using a high TrigoCor application rate, however by 3 days post-TrigoCor 
application, iturin biomarker levels on spikes from the two environments were virtually the same (Fig. 3). Iturin biomarker levels on field wheat spikes treated with a low TrigoCor application volume were detectable but low.
In both the greenhouse and in the field, iturin biomarker levels decreased over the sampling period despite the presence of Bacillus populations in significant quantities (Fig. 3). The levels of Bacillus populations recovered from spikes in both environ-

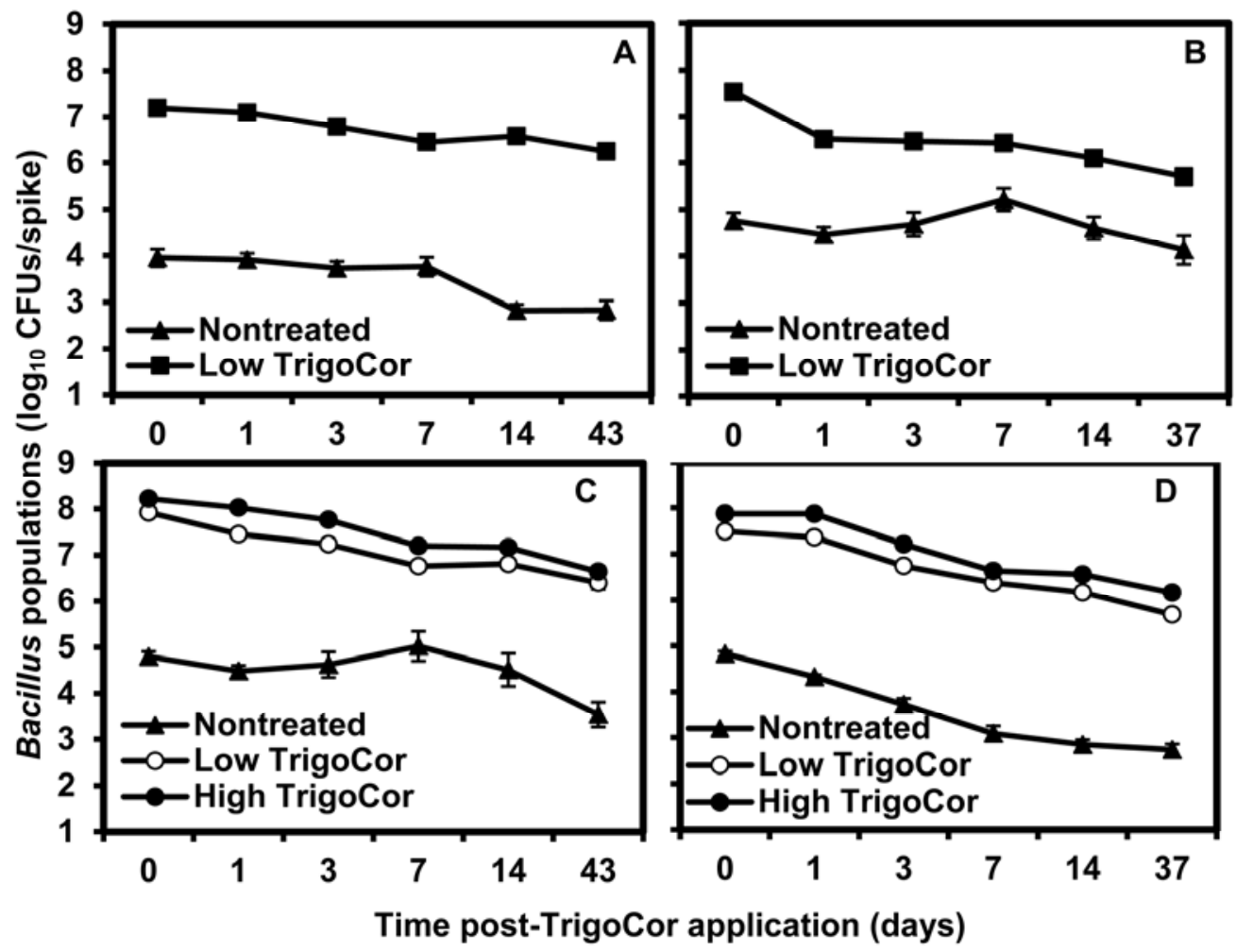

Fig. 2. Bacillus population dynamics on wheat spikes in the field following application of the biocontrol agent Bacillus amyloliquefaciens strain TrigoCor. Bacillus population levels were quantified using dilution plating from wheat spikes collected from two winter wheat field locations in A and B, 2009 and $\mathbf{C}$ and D, 2010. A and C, Ithaca, NY, field site was irrigated, whereas B and D, Aurora, NY, field site was not. In 2010, spikes were treated with a low or a high volume of TrigoCor inoculum. Corresponding inoculum concentrations, application volumes, and disease data for all years and field sites are presented in Table 1. The last time point in each series is the day of harvest. Data points represent the means of 13 (2009) and 10 (2010) individual wheat rows, using population levels from four spikes per row. Vertical lines represent the standard error of the mean for each treatment at each time point.

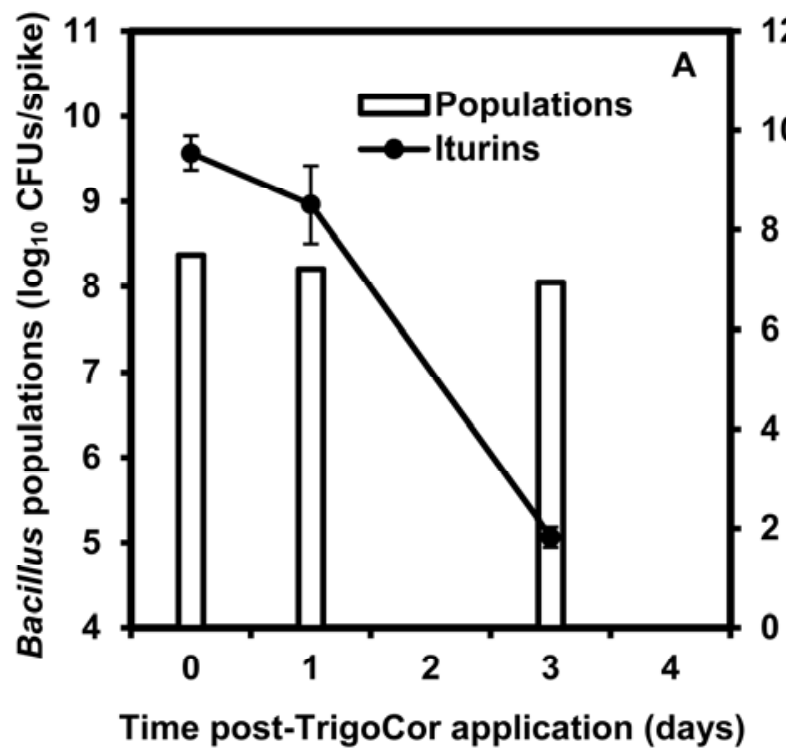

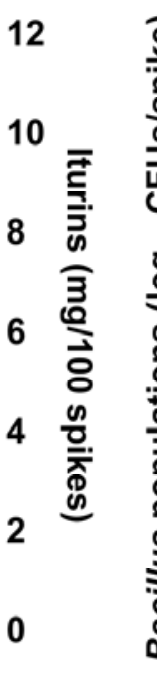

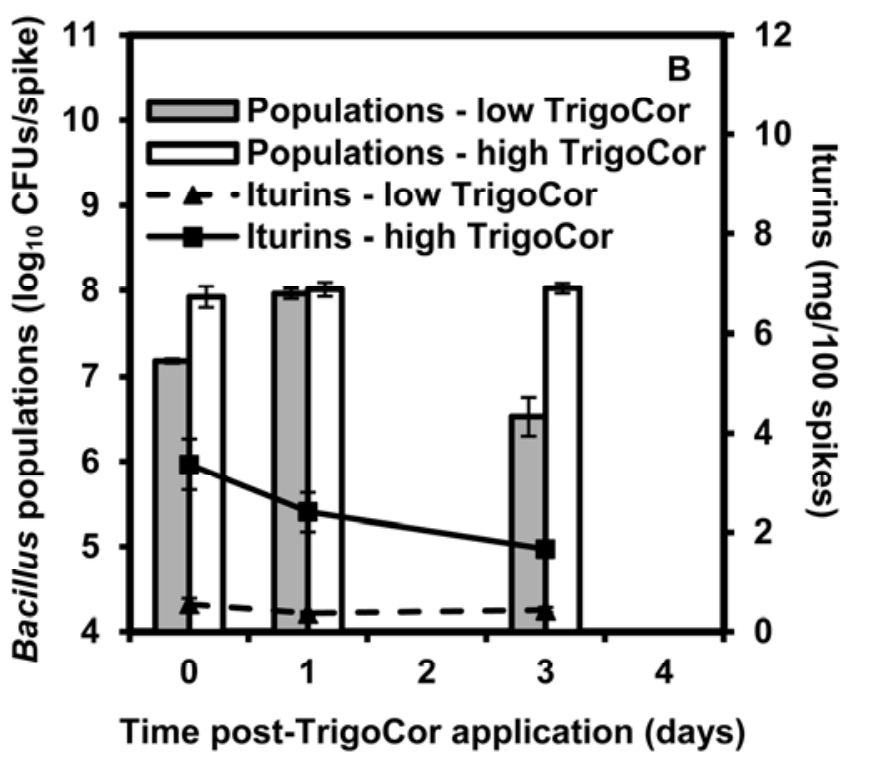

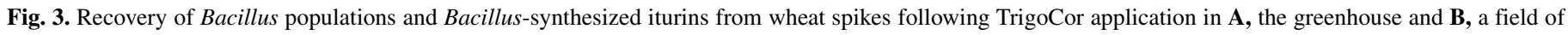

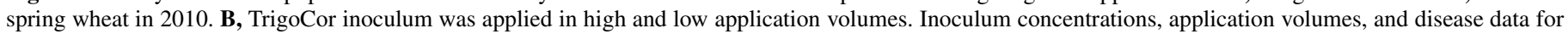

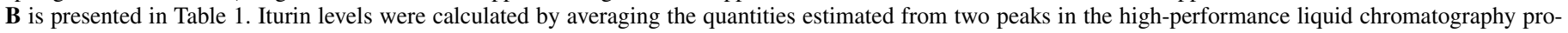

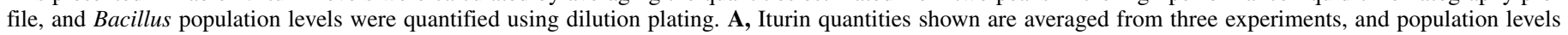

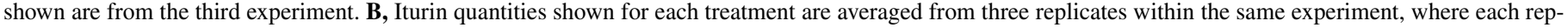

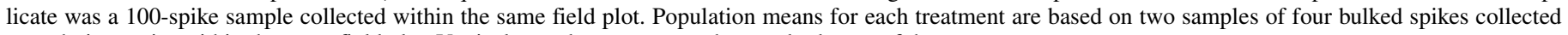
at each time point within the same field plot. Vertical error bars represent the standard error of the mean. 
ments were in keeping with the range of values observed in population dynamics trials (Figs. 1 and 2).

There were no statistically significant differences in FHB/DON among the three treatments in the field experiment (Table 1). Due to the large number of wheat spikes needed for detection of iturins, there was insufficient space available to simultaneously measure FHB/DON control in the greenhouse; however, TrigoCor applications at the rate used in these trials have consistently resulted in significant FHB/DON control (48).

Concentration effects of TrigoCor inoculum. Treatment with full strength and diluted inoculum produced Bacillus populations that approximated the range of levels observed on wheat spikes in the greenhouse and in the field, respectively. The calculated level of day 0 iturins on wheat spikes for each treatment indicated that the 10-fold dilution produced iturin levels on wheat spikes that were similar to levels in the high TrigoCor treatment in the field, and that the full-strength inoculum resulted in iturin levels roughly equivalent to those recorded previously in the greenhouse (Fig. 3, Table 2).

Treatment with full-strength inoculum provided the only statistically significant reduction in FHB and DON from the watertreated control. There were no significant differences in FHB index or DON between any of the other treatments.

Agar well diffusion assay. With each twofold reduction in iturin concentration in an agar well diffusion assay, there was a statistically significant decrease in $F$. graminearum growth inhibition (Table 3). A minimum inhibitory concentration of $0.16 \mathrm{mg}$ of iturin $/ \mathrm{ml}$ was identified. A TrigoCor culture filtrate sample run alongside the iturin dilutions produced a zone of inhibition that was statistically equivalent to the zone produced by this minimum inhibitory concentration. This assay was repeated two additional times with comparable results (data not shown).

Effect of repeated Bacillus applications in the field. Triple applications of TrigoCor in the field resulted in significant reductions in FHB index and DON compared with a nontreated control and a single TrigoCor treatment (Table 4). The triple TrigoCor application treatment had significantly lower DON, and numerically but not statistically significantly lower FHB index than did the single application of TrigoCor followed by two broth applications, indicating that nutrient addition by the two later inoculations may have contributed to the reduction in disease symptoms observed. The single TrigoCor application treatment resulted in FHB index and DON values that were not numerically

TABLE 3. Relationship between iturin concentration and Fusarium growth inhibition in well diffusion assays ${ }^{\mathrm{x}}$

\begin{tabular}{lc}
\hline Sample & ${\text { Inhibition zone radius }(\mathrm{mm})^{\mathrm{y}}}^{\mathrm{y}}$ \\
\hline Prosaro $(0.3 \% \mathrm{vol} / \mathrm{vol})^{\mathrm{z}}$ & $18.3 \pm 0.2 \mathrm{a}$ \\
Iturin $(5.00 \mathrm{mg} / \mathrm{ml})$ & $11.8 \pm 0.1 \mathrm{~b}$ \\
Iturin $(2.50 \mathrm{mg} / \mathrm{ml})$ & $10.6 \pm 0.1 \mathrm{c}$ \\
Iturin $(1.25 \mathrm{mg} / \mathrm{ml})$ & $9.2 \pm 0.1 \mathrm{~d}$ \\
Iturin $(0.63 \mathrm{mg} / \mathrm{ml})$ & $7.3 \pm 0.2 \mathrm{e}$ \\
Iturin $(0.31 \mathrm{mg} / \mathrm{ml})$ & $5.2 \pm 0.2 \mathrm{f}$ \\
TrigoCor culture filtrate & $3.2 \pm 0.2 \mathrm{~g}$ \\
Iturin $(0.16 \mathrm{mg} / \mathrm{ml})$ & $2.9 \pm 0.2 \mathrm{~g}$ \\
Iturin $(0.08 \mathrm{mg} / \mathrm{ml})$ & $0.0 \pm 0.0 \mathrm{~h}$ \\
Iturin $(0.04 \mathrm{mg} / \mathrm{ml})$ & $0.0 \pm 0.0 \mathrm{~h}$ \\
Neg control $(9 \% \mathrm{MeOH})$ & $0.0 \pm 0.0 \mathrm{~h}$ \\
\hline
\end{tabular}

${ }^{x}$ Assay was repeated three times with comparable results. Results shown are from a representative assay.

y Radius defined as the distance from the edge of the agar well to the edge of the inhibition zone. Data shown are means \pm standard error. Data represent the mean inhibition from three plates, with four radius measurements recorded and averaged per sample per plate. Means followed by a different letter are significantly different $(P<0.0001)$ according to the Tukey honestly significant difference test within the general linear model procedure.

z Prosaro 421 SC (19\% prothioconazole, 19\% tebuconazole) is a fungicide registered for use against Fusarium head blight. Rate is based on concentration applied to acre of wheat according to label (6.5 fl. oz./20 gal). different from the nontreated control, which has been a common trend in previous field trials (Table 1).

\section{DISCUSSION}

In this study we found that there were large differences in the levels of both Bacillus cells and Bacillus-synthesized iturins on wheat spikes in the greenhouse versus the field over time, although the overall trends were similar in both settings. Bacillus populations recovered from spikes in the greenhouse (Fig. 1) were typically one or more orders of magnitude higher than in the field (Fig. 2), and in both environments populations were fairly stable although in the field there was a single order of magnitude decline over 14 days. Populations in the field survived at significant levels through harvest. Despite the presence of significant populations, iturin levels declined rapidly on wheat spikes throughout 3 days post-application in both the greenhouse and in the field, but the initial iturin amount recovered from spikes was at least three times higher on spikes in the greenhouse compared with those in the field.

Our observation that Bacillus population levels are relatively constant on wheat surfaces is similar to trends reported for Bacillus populations in the soil $(2,29,30,34,50)$, which often stabilize as spores following an initial dying off of nonsporulating or slowly sporulating vegetative cells. On foliar surfaces, Bacillus populations have typically been found to decrease, often by 2 orders of magnitude or more, over a period of 14 to 15 days (1,9, $45,49,57)$, which is a larger decline than that observed in this study. Bacterial colonization in the phyllosphere is controlled by many factors (35), so it is difficult to predict why the population loss we observed was less extreme than that from other phyllosphere studies.

Our result that iturins decrease quickly on wheat spikes despite the presence of significant populations is consistent with Mizumoto (34) and Asaka and Shoda (3), who described a similar trend following Bacillus application in soil. Little information is available on Bacillus metabolite persistence in the phyllosphere, although other studies $(37,43,51)$ have reported the recovery of antifungal metabolites 5 to 6 days following application of washed Bacillus cells to detached melon leaves or apples. Possible mechanisms for the iturin loss from wheat surfaces we observed include microbial, chemical or photo-degradation, or runoff from rainfall or irrigation. However, the lack of significant rainfall $(1.3 \mathrm{~mm})$ in the 3-day period when iturin levels decreased on wheat spikes in the field in these studies suggests that washing off is likely not the

TABLE 4. Reduced contamination of grain with deoxynivalenol following multiple applications of the biocontrol agent Bacillus amyloliquefaciens strain TrigoCor in the field

\begin{tabular}{lcc}
\hline Treatment $^{\mathrm{x}}$ & FHB index & DON $(\mathrm{ppm})^{\mathrm{z}}$ \\
\hline TrigoCor applied day 0, 2, 4 & $6 \pm 0 \mathrm{a}$ & $2.45 \pm 0.25 \mathrm{a}$ \\
TrigoCor applied day 0; noninoculated & & \\
$\quad$ broth applied day 2, 4 & $13 \pm 1 \mathrm{ab}$ & $6.80 \pm 0.70 \mathrm{~b}$ \\
TrigoCor applied day 0; no treatment day 2, 4 & $20 \pm 0 \mathrm{~b}$ & $9.25 \pm 0.15 \mathrm{~b}$ \\
Nontreated & $20 \pm 4 \mathrm{~b}$ & $9.70 \pm 1.80 \mathrm{~b}$ \\
\hline
\end{tabular}

${ }^{x}$ TrigoCor inoculum cell $(\mathrm{CFU} / \mathrm{ml})$ and iturin $(\mathrm{mg} / \mathrm{ml})$ concentrations, respectively, by application day were $1.0 \times 10^{8}$ and 0.05 (day 0 ); $9.8 \times 10^{7}$ and 0.08 (day 2); and $4.0 \times 10^{7}$ and 0.04 (day 4). On all days, approximately $1.2 \mathrm{ml}$ of inoculum was applied per spike.

${ }^{y}$ FHB index $=$ a combined measure of Fusarium head blight severity and incidence. Means were arcsine-transformed prior to statistical analysis. Means not followed by the same letter were statistically different $(P=0.0286)$ according to the Tukey honestly significant difference (HSD) test within the general linear model procedure. Numbers represent the mean \pm the standard error using nontransformed data.

${ }^{\mathrm{z}} \mathrm{DON}=$ deoxynivalenol. Means were natural log-transformed prior to separation using the Tukey HSD test within the general linear model procedure. Means not followed by the same letter were statistically different $(P=0.0078)$. Numbers represent the mean \pm the standard error using nontransformed data. 
main cause of iturin loss from wheat spikes in this environment, although it is still possible that a large rain event might exacerbate iturin decline.

Fungal antagonism by iturins is the main mode of action for Bacillus biological control of FHB $(16,42)$, so information on iturin dynamics is particularly informative for understanding and enhancing disease control. We believe the role of Bacillus cells in situ to be relatively minor in FHB control, as indicated by replicated greenhouse trials in which treatment with culture filtrate provided more FHB/DON suppression than did treatment with washed cells (S. O. Kawamoto, R. H. Vaughan, D. M. Gibson, G. C. Bergstrom, and J. M. Crane, unpublished data). Furthermore, our finding that there was not a significant improvement in FHB/DON control when Bacillus populations on wheat spikes in the 2010 field trials were increased to a level initially matching that in the greenhouse (Table 1; Figs. 1 and 2C and D) suggests that cell levels do not by themselves determine the success or lack of disease control.

Most Bacillus cells are present post-application as metabolically dormant spores, which probably explains the minor contribution of these cells to disease control. The insufficient metabolite production of cells following application to wheat spikes is indicated by our result that there was a drastic decline in iturins despite the presence of significant Bacillus cell concentrations (Fig. 3). Other groups $(37,43,51)$ have reported recovery of iturins and/or fengycins following application of washed Bacillus cells to postharvest apples or to detached melon leaves, indicating that Bacillus cells may be able to produce metabolites on plant surfaces; however, it is also possible that cells can produce a small amount of metabolites in situ but that the rate of production is not large enough to compensate for the quantity that is lost.

While information on Bacillus population dynamics does not directly explain disease control, it is still useful for understanding the ecology of this BCA and for identifying strategies to improve metabolite production. For instance, we found that Bacillus cells can survive on wheat spikes in the field for at least 40 days postapplication (Fig. 2), indicating that if they can be modified to produce more antifungal compounds post-application, then they could potentially prevent infections throughout grain ripening.

Disease control in this system was dose-dependent (Tables 2 and 3), and the dose of iturins currently being applied in greenhouse experiments was already fairly close to the minimum amount needed for control, as evidenced by the fact that even a 10 -fold dilution in inoculum compromised FHB/DON suppression in the greenhouse (Table 2) and that a TrigoCor culture filtrate was not statistically more effective than the minimum iturin concentration needed for Fusarium inhibition in antibiosis assays (Table 3). Thus, any major reduction from the iturin level observed in the greenhouse, such as that observed on wheat spikes in the field, will decrease these essential Bacillus-synthesized components past the point of effectiveness. One potentially major limiting factor for FHB control by Bacillus in the field is inadequate delivery of inoculum, which by itself will reduce iturin levels below the threshold for successful control. For instance, the amount of inoculum reaching spikes in the field at a high commercial-scale rate (187 liters/ha) is 2 orders of magnitude lower than the volume delivered in the greenhouse, and an even greater reduction can be expected with application rates typical in commercial-scale agriculture (47 liters/ha for aerial application and 97 liters/ha for ground application [21,22]).

One option for enhancing BCA performance under field conditions may be increasing the concentration of metabolites in inoculum. Increased iturin concentrations in inoculum enhanced control of southern corn leaf blight, caused by Bipolaris maydis (56), and tomato damping-off, caused by Rhizoctonia solani (34). In our system, based on the minimum inhibitory concentration for Fusarium inhibition in antibiosis assays (Table 3) and on the rate of inoculum delivered to wheat spikes in the greenhouse and in field at a high commercially relevant rate, iturin concentrations in inoculum would need to be increased by a very large scale, 100to 300 -fold, to ensure that the resulting iturin levels on wheat spikes in the field would match the minimum effective level in the greenhouse (calculated at $8 \mathrm{mg}$ of iturins/100 spikes). For inoculum applied at the recommended rates for commercial-scale application (47 liters/ha for aerial application and 97 liters/ha for ground application [21,22]), iturin concentrations would need to be increased even further. In antibiosis assays, even the most concentrated iturin sample only provided a little over half the Fusarium inhibition as did a registered FHB fungicide (Table 3), showing that very high inoculum concentrations of iturins will be essential for BCAs to compete with chemical controls. Despite the importance of antifungal metabolites in control of foliar diseases, however, commercial BCA products list Bacillus CFUs as the descriptor of product activity.

Due to the rapid decline of iturins we observed on wheat spikes (Fig. 3), we expect that increasing inoculum metabolite concentrations would provide the greatest advantage for disease control in the days immediately following application. Thus, alterations in Bacillus inoculum quality would be most beneficial when controlling diseases with predictable, narrow infection periods. For diseases such as FHB where DON-contributing Fusarium infections can occur over a period of 10 or more days post-anthesis $(10,15)$, such short-term enhancements in disease control would be less advantageous. Instead, having a high level of iturins which are maintained on plant surfaces over a longer period of time may be a more reliable means of improving biocontrol efficacy. Part of the success of TrigoCor in greenhouse trials may come from the fact that Fusarium is applied to spikes 1 day after TrigoCor treatment and then the wheat is placed in a mist chamber which facilitates rapid disease development while iturin levels are high. In contrast, in field experiments although we apply Fusarium at the same time post-TrigoCor treatment, natural infections are likely occurring at later times when iturin levels are too low to be effective. When Fusarium infections in the greenhouse are delayed to 3 days post-TrigoCor application, the magnitude of FHB control resulting from TrigoCor pretreatment decreases (S. O. Kawamoto and G. C. Bergstrom, unpublished data), supporting the idea that longevity of antifungal activity is key to biocontrol success in this system.

In the 2011 field trial, we showed that a triple TrigoCor application provided significant FHB/DON suppression, whereas a single application did not (Table 4). Our assumption is that the triple application maintained high iturin levels over much of the critical FHB infection period following anthesis. The effect of repeated applications of Bacillus BCAs has also been investigated in other disease systems with mixed results $(5,18)$, indicating that the advantage of increasing metabolite longevity might be situation- or disease-dependent. Although the enhancement in biological control that we observed from repeating TrigoCor applications is useful for experimental purposes, it is likely not financially viable in a wheat commercial agriculture setting. However, multiple applications of Bacillus should be considered for crops where this method might be more economically viable, such as for highvalue horticultural crops, crops grown on a small scale, or for organic production where options for disease control are more limited. We are currently exploring other avenues for improving metabolite longevity on wheat surfaces, such as by activating metabolite production from Bacillus cells post-application or by adding stabilizers to our inoculum.

In summary, we propose that successful control of FHB/DON by Bacillus relies on adequate levels of a key antifungal compound, iturin, and that insufficient levels of this metabolite on wheat spikes in the field are responsible for the lack of disease control in this environment. Furthermore, our finding that iturins decline rapidly on wheat spikes in the field and greenhouse despite the presence of significant Bacillus populations indicates 
that Bacillus cells are not adequately replenishing lost iturins on wheat surfaces. Our results suggest that future research on enhancing Bacillus control of foliar diseases should focus on increasing the level and longevity of iturins in the phyllosphere, particularly when combating diseases with long infection periods.

\section{ACKNOWLEDGMENTS}

This research was supported by the U.S. Department of Agriculture, under agreement 59-070-4-093, and by Cornell University Hatch Project NYC 153433. This was a cooperative project with the U.S. Wheat and Barley Scab Initiative. Any opinions, findings, conclusions, or recommendations expressed in this publication are those of the authors and do not necessarily reflect the view of the U.S. Department of Agriculture. We thank P. Stachowski and his staff at the Musgrave research farm in Aurora, NY, as well as D. Benscher for their assistance planting wheat for field trials; A. Landers for kindly providing Pyranine dye; S. Kawamoto, K. Waxman, E. Burrichter, W. Di, H. Bergstrom, and C. Mahaney for general lab and field support; and Y. Dong and D. Schmale III for DON testing.

\section{LITERATURE CITED}

1. Alexandrova, M., Bazzi, C., and Lameri, P. 2002. Bacillus subtilis strain BS-F3: Colonization of pear organs and its action as a biocontrol agent. Acta Hortic. (ISHS) 590:291-297.

2. Asaka, O., Ano, T., and Shoda, M. 1996. Persistence of Bacillus subtilis RB14 and its derivative strains in soil with respect to the lpa-14 gene. J. Ferment. Bioeng. 81:1-6.

3. Asaka, O., and Shoda, M. 1996. Biocontrol of Rhizoctonia solani damping-off of tomato with Bacillus subtilis RB14. Appl. Environ. Microbiol. 62:4081-4085.

4. Bai, G. H., and Shaner, G. 2004. Management and resistance in wheat and barley to Fusarium head blight. Annu. Rev. Phytopathol. 42:135-161.

5. Baker, C., Stavely, J., and Mock, N. 1985. Biocontrol of bean rust by Bacillus subtilis under field conditions. Plant Dis. 69:770-772.

6. Bergstrom, G., and da Luz, W. C. 2005. Biocontrol for plants with Bacillus subtilis, Pseudomonas putida, and Sporobolomyces roseus. Cornell Research Foundation and Embrapa Trigo (Brazil). U.S. Patent 6,896,883 B2.

7. Bleakley, B., and Luo, Y. 1999. Biological control of Fusarium head blight (FHB) of wheat by Bacillus strains. Page 60 in: National Fusarium Head Blight Forum. University Printing, Michigan State University, East Lansing, MI.

8. Bradley, C. A., Adee, E. A., Ebelhar, S. A., Dill-Macky, R., Wiersma, J. J., Grybauskas, A. P., Kirk, W. W., McMullen, M. P., Halley, S., Milus, E. A., Osborne, L. E., Ruden, K. R., and Young, B. G. 2010. Multi-state uniform fungicide evaluations for control of Fusarium head blight and associated mycotoxins. Page 74 in: National Fusarium Head Blight Forum. University of Kentucky, Lexington, KY.

9. Collins, D. P., Jacobsen, B. J., and Maxwell, B. 2003. Spatial and temporal population dynamics of a phyllosphere colonizing Bacillus subtilis biological control agent of sugar beet Cercospora leaf spot. Biol. Con. 26:224-232.

10. Cowger, C., and Arrellano, C. 2010. Plump kernels with high deoxynivalenol linked to late Gibberella zeae infection and marginal disease conditions in winter wheat. Phytopathology 100:719-728.

11. Crane, J. M., Gibson, D. M., and Bergstrom, G. C. 2009. Ecology of Bacillus subtilis on wheat florets in relation to biological control of FHB/DON. Page 39 in: National Fusarium Head Blight Forum Proceedings. University of Kentucky, Lexington, KY.

12. Crane, J. M., Gibson, D. M., and Bergstrom, G. C. 2010. Ecology of Bacillus amyloliquefaciens on wheat florets in relation to biological control of FHB/DON. Pages 77-78 in: National Fusarium Head Blight Forum Proceedings. University of Kentucky, Lexington, KY.

13. da Luz, W. C., Stockwell, C. A., and Bergstrom, G. C. 2003. Biological control of Fusarium graminearum. Pages 381-394 in: Fusarium Head Blight of Wheat and Barley. K. J. Leonard and W. R. Bushnell, eds. The American Phytopathological Society, St. Paul, MN.

14. Del Ponte, E. M., Fernandes, J. M. C., and Bergstrom, G. C. 2007. Influence of growth stage on Fusarium head blight and deoxynivalenol production in wheat. J. Phytopathol. 155:577-581.

15. Dunlap, C., Schisler, D., Price, N., and Vaughn, S. 2011. Cyclic lipopeptide profile of three Bacillus subtilis strains; antagonists of Fusarium head blight. J. Microbiol. 49:603-609.

16. Engle, J. S., Lipps, P. E., and Miller, D. 2003. Fusarium head blight severity scale for winter wheat. Published online by The Ohio State University, Colombus, OH. ohioline.osu.edu/ac-fact/0049.html
17. Fernando, W. G. D., Nakkeeran, S., Zhang, Y., and Savchuk, S. 2007. Biological control of Sclerotinia sclerotiorum (Lib.) de Bary by Pseudomonas and Bacillus species on canola petals. Crop Prot. 26:100-107.

18. Francl, L., Shaner, G., Bergstrom, G., Gilbert, J., Pedersen, W., DillMacky, R., Sweets, L., Corwin, B., Jin, Y., Gallenberg, D., and Wiersma, J. 1999. Daily inoculum levels of Gibberella zeae on wheat spikes. Plant Dis. 83:662-666.

19. Halley, S., Misek, K., and Kinzer, K. 2009. Evaluation of biological alternatives for single treatment fungicide on hard red spring wheat for controlling Fusarium head blight. Page 49 in: National Fusarium Head Blight Forum Proceedings. University of Kentucky, Lexington, KY.

20. Halley, S., Van Ee, G., Hofman, V., McMullen, M., Hollingsworth, C., and Ruden, B. 2008. Recommended fungicide application techniques for FHB suppression in small grains with ground applicators. Published online by NDSU Extension Service, Fargo, ND. scabsmart.org/PDFs/ae1314.pdf

21. Hofman, V., Halley, S., Van Ee, G., Hollingsworth, C., McMullen, M., and Ruden, B. 2007. Aerial application of fungicide for the suppression of Fusarium head blight in small grains. Published online by NDSU Extension Service, Fargo, ND. scabsmart.org/PDFs/ae1327.pdf

22. Jacobsen, B. J. 2006. Biological control of plant diseases by phyllosphere applied biological control agents. Pages 133-147 in: Microbial Ecology of Aerial Plant Surfaces. M. J. Bailey, A. K. Lilley, T. M. Timms-Wilson, and P. T. N. Spenser-Phillips, eds. CAB International, Oxfordshire, UK.

23. Jacobsen, B. J., Zidack, N. K., and Larson, B. J. 2004. The role of Bacillus-based biological control agents in integrated pest management systems: Plant diseases. Phytopathology 94:1272-1275.

24. Jochum, C. C., Osborne, L. E., and Yuen, G. Y. 2006. Fusarium head blight biological control with Lysobacter enzymogenes strain C3. Biol. Con. 39:336-344.

25. Kawamoto, S. O., Stockwell, C. M., Otis, D. J., Cox, W. J., Sorrells, M. E., and Bergstrom, G. C. 2002. Evaluation of foliar fungicides and bioprotectants for control of Fusarium head blight of winter wheat in New York in 2002. Pages 92-95 in: National Fusarium Head Blight Forum Proceedings. University of Kentucky, Lexington, KY.

26. Khan, M. R., and Doohan, F. M. 2009. Comparison of the efficacy of chitosan with that of a fluorescent pseudomonad for the control of Fusarium head blight disease of cereals and associated mycotoxin contamination of grain. Biol. Con. 48:48-54.

27. Khan, N. I., Schisler, D. A., Boehm, M. J., Lipps, P. E., and Slininger, P. J. 2004. Field testing of antagonists of Fusarium head blight incited by Gibberella zeae. Biol. Con. 29:245-255.

28. Khan, N. I., Schisler, D. A., Boehm, M. J., Slininger, P. J., and Bothast, R. J. 2001. Selection and evaluation of microorganisms for biocontrol of Fusarium head blight of wheat incited by Gibberella zeae. Plant Dis. 85:1253-1258

29. Kim, D.-S., Weller, D. M., and Cook, R. J. 1997. Population dynamics of Bacillus sp. L324-92R12 and Pseudomonas fluorescens 2-79RN10 in the rhizosphere of wheat. Phytopathology 87:559-564.

30. Kokalis-Burelle, N., Kloepper, J. W., and Reddy, M. S. 2006. Plant growth-promoting rhizobacteria as transplant amendments and their effects on indigenous rhizosphere microorganisms. Appl. Soil Ecol. 31:91-100.

31. McMullen, M., Bergstrom, G., De Wolf, E., Dill-Macky, R., Hershman, D., Shaner, G., and Van Sanford, D. 2012. A unified effort to fight an enemy of wheat and barley: Fusarium head blight. Plant Dis. DOI: 10.1094/PDIS-03-12-0291-FE

32. McMullen, M., Jones, R., and Gallenberg, D. 1997. Scab of wheat and barley: A re-emerging disease of devastating impact. Plant Dis. 81:13401348.

33. Mesterházy, Á., Bartók, T., and Lamper, C. 2003. Influence of wheat cultivar, species of Fusarium, and isolate aggressiveness on the efficacy of fungicides for control of Fusarium head blight. Plant Dis. 87:11071115 .

34. Mizumoto, S., Hirai, M., and Shoda, M. 2007. Enhanced iturin A production by Bacillus subtilis and its effect on suppression of the plant pathogen Rhizoctonia solani. Appl. Microbiol. Biotechnol. 75:1267-1274.

35. O'Brien, R. D. 1989. Effect of plant species and environmental conditions on epiphytic population sizes of Pseudomonas syringae and other bacteria. Phytopathology 79:619.

36. Ongena, M., and Jacques, P. 2008. Bacillus lipopeptides: Versatile weapons for plant disease biocontrol. Trends Microbiol. 16:115-125.

37. Ongena, M., Jacques, P., Toure, Y., Destain, J., Jabrane, A., and Thonart, P. 2005. Involvement of fengycin-type lipopeptides in the multifaceted biocontrol potential of Bacillus subtilis. Appl. Microbiol. Biotechnol. 69:29-38.

38. Palazzinia, J. M., Ramirez, M. L., Torres, A. M., and Chulze, S. N. 2007. Potential biocontrol agents for Fusarium head blight and deoxynivalenol production in wheat. Crop Prot. 26:1702-1710.

39. Paul, P. A., Lipps, P. E., Hershman, D. E., McMullen, M. P., Draper, M. A., and Madden, L. V. 2008. Efficacy of triazole-based fungicides for 
Fusarium head blight and deoxynivalenol control in wheat: A multivariate meta-analysis. Phytopathology 98:999-1011.

40. Pérez-García, A., Romero, D., Zeriouh, H., and Vicente, A. 2011. Biological control of phytopathogenic fungi by aerobic endosporeformers. Pages 157-180 in: Endospore-forming Soil Bacteria. N. A. Logan and P. Vos, eds. Springer, Berlin, Heidelberg.

41. Pryor, S. W., Gibson, D. M., Krasnoff, S. B., and Walker, L. P. 2006. Identification of antifungal compounds in a biological control product using a microplate inhibition bioassay. Trans. ASAE 49:1643-1649.

42. Pryor, S. W., Siebert, K. J., Gibson, D. M., Gossett, J. M., and Walker, L. P. 2007. Modeling production of antifungal compounds and their role in biocontrol product inhibitory activity. J. Agric. Food Chem. 55:9530-9536.

43. Romero, D., de Vicente, A., Rakotoaly, R. H., Dufour, S. E., Veening, J. W., Arrebola, E., Cazorla, F. M., Kuipers, O. P., Paquot, M., and PerezGarcia, A. 2007. The iturin and fengycin families of lipopeptides are key factors in antagonism of Bacillus subtilis toward Podosphaera fusca. Mol. Plant-Microbe Interact. 20:430-440.

44. Rooney, A. P., Price, N. P. J., Ehrhardt, C., Swezey, J. L., and Bannan, J. D. 2009. Phylogeny and molecular taxonomy of the Bacillus subtilis species complex and description of Bacillus subtilis subsp. inaquosorum subsp. nov. Int. J. Syst. Evol. Microbiol. 59:2429-2436.

45. Scherm, H., Ngugi, H. K., Savelle, A. T., and Edwards, J. R. 2004. Biological control of infection of blueberry flowers caused by Monilinia vaccinii-corymbosi. Biol. Con. 29:199-206.

46. Schisler, D. A., Khan, N. I., Boehm, M. J., and Slininger, P. J. 2002. Greenhouse and field evaluation of biological control of Fusarium head blight on durum wheat. Plant Dis. 86:1350-1356.

47. Stockwell, C. A., Bergstrom, G. C., and da Luz, W. C. 2001. Biological control of Fusarium head blight with Bacillus subtilis TrigoCor 1448. Pages 91-95 in: National Fusarium Head Blight Forum Proceedings. University of Kentucky, Lexington, KY.

48. Stockwell, C. A., da Luz, W. C., and Bergstrom, G. C. 1997. Biocontrol of wheat scab with microbial antagonists. (Abstr.) Phytopathology 87(suppl.): S94.

49. Thornton, H. A., Savelle, A. T., and Scherm, H. 2008. Evaluating a di- verse panel of biocontrol agents against infection of blueberry flowers by Monilinia vaccinii-corymbosi. Biocon. Sci. Technol. 18:391-407.

50. Tokuda, Y., Ano, T., and Shoda, M. 1995. Survival of Bacillus subtilis NB22 and its transformant in soil. Appl. Soil Ecol. 2:85-94.

51. Touré, Y., Ongena, M., Jacques, P., Guiro, A., and Thonart, P. 2004. Role of lipopeptides produced by Bacillus subtilis GA1 in the reduction of grey mould disease caused by Botrytis cinerea on apple. J. Appl. Microbiol. 96:1151-1160.

52. Waxman, K. D., and Bergstrom, G. 2009. Evaluation of integrated FHB management methods under moderate and severe epidemics in New York. Pages 90-92 in: National Fusarium Head Blight Forum Proceedings. University of Kentucky, Lexington, KY.

53. Waxman, K. D., Bergstrom, G. C., Richtmyer, R. J., and Hahn, R. R. 2009. Evaluation of integrated methods for management of Fusarium head blight and foliar diseases of winter wheat in New York, 2009. Plant Disease Management Reports 4:CF016. Online publication. doi: 10.1094/PDMR04

54. Willyerd, K. T., Li, C., Madden, L. V., Bradley, C. A., Bergstrom, G. C., Sweets, L. E., McMullen, M., Ransom, J. K., Grybauskas, A., Osborne, L., Wegulo, S. N., Hershman, D. E., Wise, K., Bockus, W. W., Groth, D. Dill-Macky, R., Milus, E., Esker, P. D., Waxman, K. D., Adee, E. A., Ebelhar, S. E., Young, B. G., and Paul, P. A. 2012. Efficacy and stability of integrating fungicide and cultivar resistance to manage Fusarium head blight and deoxynivalenol in wheat. Plant Dis. 96:957-967.

55. Xue, A. G., Voldeng, H. D., Savard, M. E., Fedak, G., Tian, X., and Hsiang, T. 2009. Biological control of Fusarium head blight of wheat with Clonostachys rosea strain ACM941. Can. J. Plant Pathol. 31:169-179.

56. Ye, Y. F., Li, Q. Q., Fu, G., Yuan, G. Q., Miao, J. H., and Lin, W. 2012. Identification of antifungal substance (Iturin A(2)) produced by Bacillus subtilis B47 and its effect on Southern corn leaf blight. J. Integr. Agric. 11:90-99.

57. Yuen, G. Y., Godoy, G., Steadman, J. R., Kerr, E. D., and Craig, M. L. 1991. Epiphytic colonization of dry edible bean by bacteria antagonistic to Sclerotinia sclerotiorum and potential for biological control of white mold disease. Biol. Con. 1:293-301. 